\title{
COVID-19 threatens health systems in sub-Saharan Africa: the eye of the crocodile
}

\author{
Elijah Paintsi| ${ }^{1,2,3,4}$
}

'Department of Pediatrics and 2Department of Pharmacology, School of Medicine, ${ }^{3}$ Department of Epidemiology of Microbial Diseases, School of Public Health, and ${ }^{4}$ Yale School of Management, New Haven, Connecticut, USA.

$\mathbf{T}$ he threat of coronavirus disease 2019 (COVID-19) to health systems in subSaharan Africa (SSA) can be compared metaphorically to a lake in Africa infested with a bask of crocodiles and the saying "the eye of the crocodile." In the lake, only the eyes of the crocodile appear on the surface while the rest of the body is submerged in water. In this Viewpoint, the eyes and the body of the crocodile represent the public health preparedness and health systems, respectively, in SSA. SSA has had multiple epidemics, including, in the last 3 decades, HIV and Ebola virus. Interestingly, HIV, Ebola virus, and SARS-CoV-2 are all of zoonotic origin. HIV resulted from cross-species transfer of simian immunodeficiency virus from chimpanzees, found in eastern and central Africa, to humans (1). Ebola virus was discovered in humans during concurrent outbreaks in the Democratic Republic of Congo and the Sudan in $1976(2,3)$. It is believed that bats are the natural hosts of Ebola virus. SARS-CoV-2 also originated from bats found in caves in China. Although HIV and Ebola originated in Africa, SARS-CoV-2 was imported from China. This Viewpoint discusses the potential impact of the COVID-19 epidemic on already-fragile health systems in SSA and forecasts lessons likely to be learned from COVID-19 in SSA.

\section{Origin and virology of SARS- CoV-2}

Coronaviruses are members of the subfamily Coronavirinae in the family of Coronaviridae and the order Nidovirales. The subfamily Coronavirinae comprises four genera - Alphacoronavirus, Betacoronavirus, Gammacoronavirus, and Deltacoronavirus. Alphacoronavirus and betacoronavirus infect only mammals, while gammacoro- navirus and deltacoronavirus can infect both birds and mammals (4). Most coronaviruses that infect humans $(\mathrm{HCoV}$ NL63, HCoV-229E, HCoV-OC43, and HCoV-HKU1) cause mild upper respiratory infections in immunocompetent hosts; however, two coronaviruses that are new to humans and highly pathogenic caused epidemics in 2002-2003 (SARS-CoV) and 2012-2015 (Middle East respiratory syndrome coronavirus, MERS-CoV). Several coronaviruses that are genetically related to SARS-CoV (SARSr-CoVs) have been identified in bats from China, southeast Asia, Europe, and Africa (5-7). In a 5-year surveillance of SARSr-CoVs found in caves in Yunnan Province, China, investigators discovered 11 novel strains of SARSr-CoV in multiple species of horseshoe bats (8). Just a few years after their discovery, SARSCoV-2 emerged as the seventh human coronavirus. SARS-CoV-2 shares $79.5 \%$ sequence homology with SARS-CoV (9). SARS-CoV-2 is genetically closer to two bat-derived coronavirus strains - bat-SLCoVZC45 and bat-SL-CoVZXC21 (10).

SARS-CoV-2, like other coronaviruses, is an enveloped, single-strand, positivesense RNA virus. The envelope spike protein, which determines host cell tropism and transmissibility, mediates receptor binding and membrane fusion (11). Like SARS-CoV, SARS-CoV-2 uses human angiotensinconverting enzyme II receptor for cell entry. The structure of its receptor-binding domain is similar to that of SARS-CoV, although there are a few variations in amino acids at key residues (10). Although its genome encodes an exonuclease enzyme, it still has a relatively high mutation rate per genome replication. Thus, it may easily adapt to its new host and become efficiently transmitted from person to person.

Conflict of interest: The author has declared that no conflict of interest exists.

Importation and spread of the COVID-19 epidemic in Africa

In December 2019, an outbreak of unexplained cases of pneumonia was reported in Wuhan, Hubei Province, China (12). By January 7, 2020, the etiological agent was identified as a novel coronavirus (SARSCoV-2), and the syndrome of clinical manifestations was termed COVID-19. Soon COVID-19 cases were imported from China to other countries; Africa was not spared because of the high volume of air traffic and trade between China and Africa.

To emphasize the urgency to detect and to contain COVID-19 and the threat that the epidemic posed to Africa, the director of the Africa Centres for Disease Control and Prevention (Africa CDC), Dr. John Nkengasong, said: "If we do not detect and contain disease outbreaks early, we cannot achieve our developmental goals" (13). On February 14, the first case of COVID-19 in Africa was reported from Cairo by the Egyptian Ministry of Health and Population. The first case in Cairo was an asymptomatic individual who was identified through contact screening of an index case who travelled from China to Cairo between January 21 and February 4 on a business trip and tested positive for SARS-CoV-2 on February 11 in China (14). On February 27 Nigeria reported a case of COVID-19, the first case in subSaharan Africa (SSA), in an individual who had traveled from Italy to Lagos, Nigeria. He was immediately isolated, and contact tracing revealed 216 individuals linked to this index case (15). As Africa braced for the epidemic, the hope was that all cases would continue to be travel related and not from community transmission.

\section{Uptake of COVID-19 in Africa}

As of March 31, 2020, there were 5389 cases reported in Africa (Figure 1A) (16). This number may just be the "eye of the crocodile" as community transmission is 
A

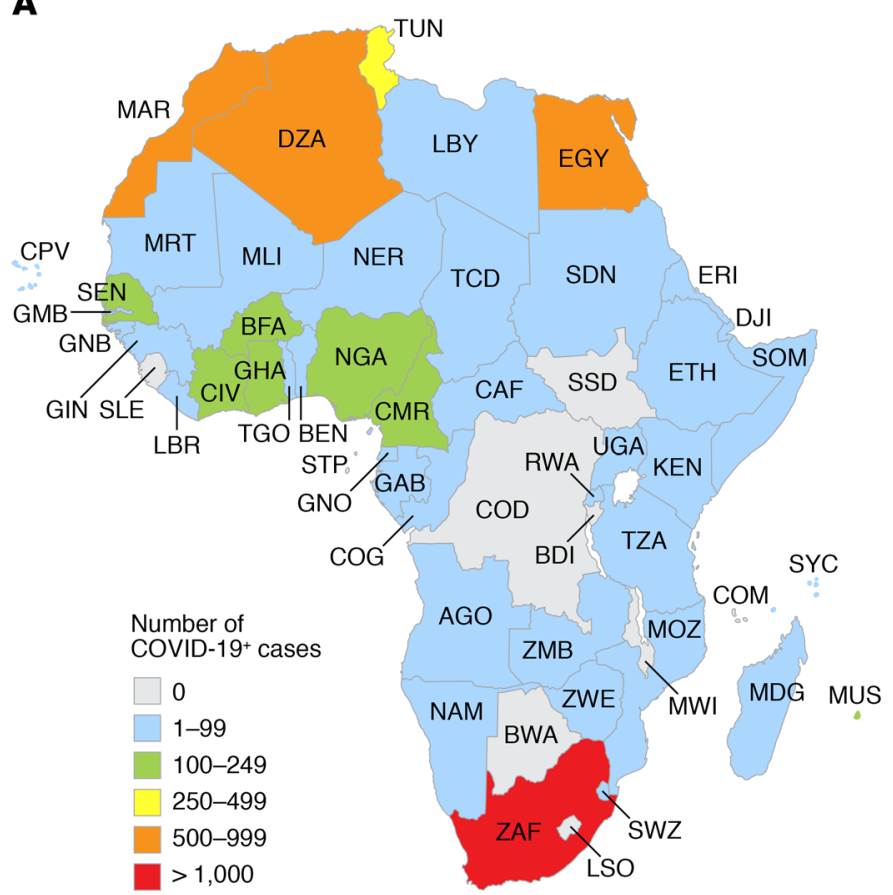

\section{B}

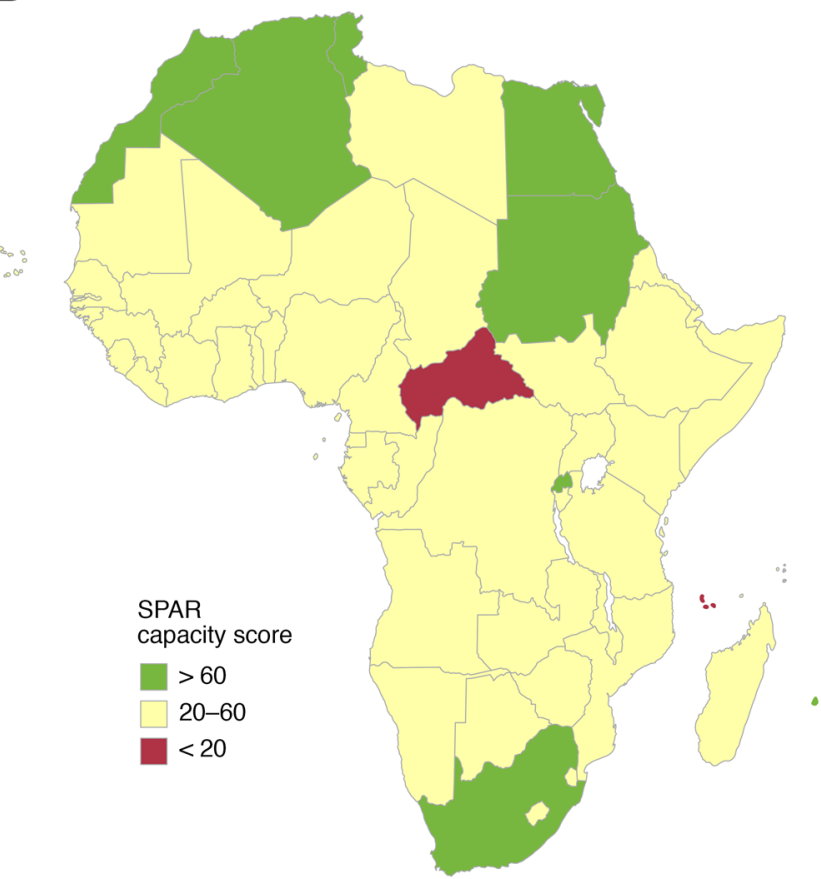

Figure 1. COVID-19 incidence and capacity of African countries to detect and respond to a health emergency. (A) The reported incidence of COVID-19 cases as of March 31, 2020. Data derived from the Johns Hopkins University Center for Systems Science and Engineering COVID-19 tracker (https://www.arcgis. com/apps/opsdashboard/index.html\#/bda7594740fd40299423467b48e9ecf6) (16). (B) State Party Self-Assessment Annual Reporting (SPAR) capacity scores, a metric of infrastructure and preparedness to handle health emergencies. A higher score indicates greater capacity. Figure adapted with permission from Lancet (22). AGO, Angola; BDI, Burundi; BEN, Benin; BFA, Burkina Faso; BWA, Botswana; CAF, Central African Republic; CIV, Côte d'Ivoire; CMR, Cameroon; COD, Democratic Republic of the Congo; COG, Republic of the Congo; COM, Comoros; CPV, Cape Verde; DJI, Djibouti; DZA, Algeria; EGY, Egypt; ERI, Eritrea; ETH, Ethiopia; GAB, Gabon; GHA, Ghana; GIN, Guinea; GMB, Gambia; GNB, Guinea-Bissau; GNQ, Equatorial Guinea; KEN, Kenya; LBR, Liberia; LBY, Libya; LSO, Lesotho; MAR, Morocco; MDG, Madagascar; MLI, Mali; MOZ, Mozambique; MRT, Mauritania; MUS, Mauritius; MWI, Malawi; NAM, Namibia; NER, Niger; NGA, Nigeria; RWA, Rwanda; SDN, Sudan; SEN, Senegal; SLE, Sierra Leone; SOM, Somalia; SSD, South Sudan; STP, São Tomé and Príncipe; SWZ, eSwatini; TCD, Chad; TCO, Togo; TUN, Tunisia; TZA, Tanzania; UGA, Uganda; ZAF, South Africa; ZMB, Zambia; ZWE, Zimbabwe.

occurring in Africa. Moreover, there are reports of shortages of SARS-CoV-2 testing kits in most countries in Africa. So far, only seven countries in SSA have not reported cases of COVID-19 - Burundi, Comoros, Democratic Republic of the Congo, Lesotho, Malawi, São Tomé and Príncipe, and South Sudan (16). The main drivers of the extent and the direction of the COVID-19 pandemic in Africa will be characteristics of SARS-CoV-2 and the robustness of the public health preparedness of the affected countries.

We are still learning about the infectiousness $\left(R_{0}\right.$, reproduction number), incubation period, routes of transmission, duration of viral shedding, and duration of stability of SARS-CoV-2. Based on the epidemiology of COVID-19 in China, the $R_{O}$ is estimated to be 2.5 to 2.9 (17). In contrast, the $R_{0}$ of both SARS-CoV and MERS$\mathrm{CoV}$ was less than 2. In comparison, the $R_{0}$ of the Spanish influenza (1918-1919) - which killed about 50 million people worldwide - was about 1.8 . The high $R_{0}$ of SARS-CoV-2 potentially increases its transmissibility. Also, there are reports that individuals infected with SARS-CoV-2 could transmit the virus before becoming symptomatic (18). These characteristics of SARS-CoV-2 must be taken into consideration in designing intervention strategies.

Despite efforts by governments in Africa and their development partners, there are still major gaps in implementation of the full tenets of the 2005 International Health Regulations (IHR). Most countries in SSA continue to fall short of achieving the core capacities of IHR (i.e., Legislation, Policy and Finance, Coordination and a National IHR Focal Point Communication, Surveillance, Response, Preparedness, Risk Communication, Human Resource Capacity, Laboratory, Potential Hazards, Points of Entry). The World Health Organization's (WHO's) Joint External Evaluation reports suggest most SSA countries are not equipped to respond adequately to an IHR hazard, such as COVID-19 (19), despite the fact that the region is perennially plagued with epidemics and pandemics (20).

Is Africa prepared and equipped to deal with COVID-19? To answer this question, the 2018 State Party Self-Assessment Annual Reporting (SPAR) (21), a component of the WHO Monitoring and Evaluation Framework, for all African countries, was used. The SPAR scores all the indicators under each of the IHR core capacities and gives a composite score ranging from 0 to 100 (increasing levels of capacity and decreasing vulnerability) (22). As shown in Figure 1B, only eight countries had a SPAR score of 60 or more out of 100 - Algeria scored 80, Egypt scored 82, Mauritius scored 62, Morocco scored 75, Rwanda scored 67, South Africa scored 66, Sudan scored 65, and Tunisia scored 66; only four of these countries are in SSA. The countries with the least capability and the most vulnerability to IHR hazards were the 
Central African Republic and Comoros, with SPAR scores of 13 and 19, respectively.

In preparation for the inevitable importation of SARS-CoV-2 to Africa, the Africa CDC established the Africa Task Force for Novel Coronavirus on February 3, 2020. In partnership with the WHO and African countries, the Africa Task Force had six strategies: (a) laboratory diagnosis; (b) surveillance, including screening at points of entry and cross-border activities; (c) prevention and control of infections in health care facilities; (d) clinical management of people with severe COVID-19; (e) risk communication and community engagement; and (f) supply chain management and stockpiles. Thus far, most countries are enforcing these strategies with assistance from Africa CDC, WHO, and development partners. However, as there are for other countries dealing with the COVID-19 epidemic, there are several challenges. Over 43 African countries are now able to test for SARS-CoV-2 (personal communication, Africa CDC). However, test kits are in short supply, making it difficult to know the true extent of the epidemic in Africa. The capacity and infrastructure for disease surveillance in Africa are also not uniform (Figure 1B). For instance, screening of travelers is not perfect, and the quality of screening may differ depending on the point of entry into a country. Screening generally is better at airports than at either sea or land entry points, similar to what occurred during the Ebola epidemic. The science and implementation of infection prevention and control in health facilities in SSA are still in early stages (23-25). The Ebola virus outbreak in west Africa highlighted the challenges with risk communication and community engagement during an epidemic. The level of education and the local belief systems were inextricably linked with successful communication as well as prevention and control of the outbreak (26). Thus, there is a major need for ongoing health literacy campaigns aimed at the general population to help detect, report, and respond rapidly to COVID-19.

\section{Implications of a COVID-19} surge for health systems in SSA The ability of African countries to absorb the surge of patients with COVID-19, if it happens, will depend on "the body of the crocodile," i.e., existing health systems. A well-functioning health system is built on a multitude of factors, including trained and motivated health workers, well-maintained infrastructure, and a reliable supply of medicines and personal protective equipment, and must be backed by adequate funding, strong health plans, and evidence-based policies (27). Although such goals may seem aspirational for many countries, when epidemics such as COVID-19 strike, the quality of health systems determines both the socioeconomic and the death tolls on a country. If this epidemic continues, more patients will need hospitalization and intensive care, which will stretch an already-fragile health system in Africa.

We have seen the health systems of the United States, Italy, Spain, and the United Kingdom buckle under the surge of COVID-19 and the need to care for severely ill patients in intensive care units (ICUs). This strain is all the more reason that Africa must scale up its containment and mitigation strategies - quarantine, isolation, and social distancing. SSA has the fewest hospital beds per 1000 people in the world, with most countries having fewer than 1 hospital bed per 1000 people (28). Is any country in SSA ready to take care of the $20 \%$ to $25 \%$ of COVID-19 patients who may need intensive care? There is a dearth of information on the capacity to provide care for critically ill patients in ICUs in Africa. South Africa and Uganda have about 75 and 1 ICU bed per million population, respectively (29), compared with about 336 ICU beds per million population in the United States (30). Most countries in SSA have fewer than 20 ICU beds for their entire population (29).

\section{Preparing for the next epidemic in SSA}

COVID-19 reminds us again that Africa is not exempt from pandemics (either imported to or originating from Africa). Posterity will not forgive us if we fail to learn the following recurring lessons: (a) the need to improve the epidemic preparedness infrastructure and health systems of SSA countries; (b) the need for special and urgent campaigns to establish functional infection prevention and control practices in health care facilities across Africa; (c) the need for Africa and its development partners to take the Global
Health Security Agenda (GHSA) seriously and make commensurate financial commitments to GHSA; (d) the need for research and development in SSA - African governments should make political and substantial funding commitments to research and active surveillance activities that could help to detect and to contain epidemics; and (e) the need for academic research partnership with intra- and intercontinental universities to define the research agenda and build research culture, infrastructure, and capacity in SSA. Ultimately, global partnerships are needed to better define the research agenda and build a robust health infrastructure that provides SSA the capacity to respond to the next epidemic.

\section{Acknowledgments}

I am grateful to Eugene Shapiro and Elliott Paintsil for their helpful comments and suggestions.

Address correspondence to: Elijah Paintsil, Child Health Research Center, Department of Pediatrics, Yale School of Medicine, 464 Congress Avenue, New Haven, Connecticut 06529, USA. Phone: 203.785.6101; Email: elijah.paintsil@yale.edu.

1. Hahn BH, Shaw GM, De Cock KM, Sharp PM. AIDS as a zoonosis: scientific and public health implications. Science. 2000;287(5453):607-614.

2. WHO. Ebola haemorrhagic fever in Zaire, 1976. Bull World Health Organ. 1978;56(2):271-293.

3. WHO. Ebola haemorrhagic fever in Sudan, 1976. Report of a WHO/International Study Team. Bull World Health Organ. 1978;56(2):247-270.

4. Woo PC, et al. Discovery of seven novel Mam malian and avian coronaviruses in the genus deltacoronavirus supports bat coronaviruses as the gene source of alphacoronavirus and betacoronavirus and avian coronaviruses as the gene source of gammacoronavirus and deltacoronavirus. J Virol. 2012;86(7):3995-4008.

5. Li W, et al. Bats are natural reservoirs of SARS-like coronaviruses. Science. 2005;310(5748):676-679.

6. Gouilh MA, Puechmaille SJ, Gonzalez JP, Teeling E, Kittayapong P, Manuguerra JC. SARS-Coronavirus ancestor's foot-prints in South-East Asian bat colonies and the refuge theory. Infect Genet Evol. 2011;11(7):1690-1702.

7. Tong S, et al. Detection of novel SARS-like and other coronaviruses in bats from Kenya. Emerging Infect Dis. 2009;15(3):482-485.

8. Hu B, et al. Discovery of a rich gene pool of bat SARS-related coronaviruses provides new insights into the origin of SARS coronavirus. PLoS Pathog. 2017;13(11):e1006698.

9. Zhu N, et al. A novel coronavirus from patients 
with pneumonia in China, 2019. N Engl JMed. 2020;382(8):727-733.

10. Lu R, et al. Genomic characterisation and epidemiology of 2019 novel coronavirus: implications for virus origins and receptor binding. Lancet. 2020;395(10224):565-574.

11. Li F. Structure, function, and evolution of coronavirus spike proteins. Annu Rev Virol. 2016;3(1):237-261.

12. Zhou P, et al. A pneumonia outbreak associated with a new coronavirus of probable bat origin. Nature. 2020;579(7798):270-273.

13. Makoni M. Africa prepares for coronavirus. Lancet. 2020;395(10223):483.

14. WHO. Update on COVID-19 in the Eastern Mediterranean Region. http://www.emro.who. int/media/news/update-on-covid-19-in-theeastern-mediterranean-region.html. Updated February 16, 2020. Accessed March 30, 2020.

15. Nigeria Centre for Disease Control. COVID-19 Outbreak in Nigeria: Situation Report. March 9, 2020. https://ncdc.gov.ng/diseases/sitreps/?cat $=14 \&$ name $=$ An $\% 20$ update $\% 20$ of $\% 20$ COVID-19\%20outbreak\%20in\%20Nigeria. Accessed March 31, 2020.

16. Center for Systems Science and Engineering. Coronavirus COVID-19 Global Cases by the Center for Systems Science and Engineering (CSSE) at Johns Hopkins University (JHU). http://www.arcgis.com/apps/ opsdashboard/index.html\#/bda7594740fd- 40299423467b48e9ecf6. Updated March 31, 2020. Accessed March 31, 2020.

17. Wu JT, Leung K, Leung GM. Nowcasting and forecasting the potential domestic and international spread of the 2019-nCoV outbreak originating in Wuhan, China: a modelling study. Lancet. 2020;395(10225):689-697.

18. Chan JF, et al. A familial cluster of pneumonia associated with the 2019 novel coronavirus indicating person-to-person transmission: a study of a family cluster. Lancet. 2020;395(10223):514-523.

19. WHO. WHO African Region: JEE Mission Report 2020. http://www.who.int/ihr/procedures/mission-reports-africa/en. Accessed March 30, 2020.

20. Talisuna AO, et al. Spatial and temporal distribution of infectious disease epidemics, disasters and other potential public health emergencies in the World Health Organisation Africa region, 2016-2018. Global Health. 2020;16(1):9.

21. WHO. Electronic State Parties Self-Assessment Annual Reporting Tool 2018. http://extranet. who.int/e-spar. Updated 2019. Accessed March 30, 2020.

22. Gilbert M, et al. Preparedness and vulnerability of African countries against importations of COVID-19: a modelling study. Lancet. 2020;395(10227):871-877.

23. Asare A, Enweronu-Laryea CC, Newman MJ. Hand hygiene practices in a neonatal intensive care unit in Ghana. J Infect Dev Ctries.
2009;3(5):352-356.

24. Friday O, et al. Assessment of infection control practices in maternity units in Southern Nigeria. Int J Qual Health Care. 2012;24(6):634-640.

25. Reda AA, Fisseha S, Mengistie B, Vandeweerd JM. Standard precautions: occupational exposure and behavior of health care workers in Ethiopia. PLOS ONE. 2010;5(12):e14420.

26. Chan M. Ebola virus disease in West Africa-no early end to the outbreak. N Engl J Med. 2014;371(13):1183-1185.

27. WHO. Everybody's Business: Strengthening Health Systems to Improve Health Outcomes. http://www.who.int/healthsystems/strategy/ everybodys_business.pdf. 2007. Accessed March 30, 2020.

28. World Bank. Hospital beds per 1000 people: 1960 - 2014: World Bank - World Development Indicators; 2014. http://data.worldbank.org/data-catalog/world-development-indicators. Updated March 18, 2020. Accessed March 30, 2020.

29. Murthy S, Leligdowicz A, Adhikari NK. Intensive care unit capacity in low-income countries: a systematic review. PLOS ONE. 2015;10(1):e0116949.

30. Wallace DJ, Angus DC, Seymour CW, Barnato $\mathrm{AE}, \mathrm{Kahn}$ JM. Critical care bed growth in the United States. A comparison of regional and national trends. Am J Respir Crit Care Med. 2015;191(4):410-416. 